\title{
AVALIAÇÃO EM MATEMÁTICA: UMA LEITURA DE CONCEPÇÕES E ANÁLISE DO VIVIDO NA SALA DE AULA
}

\section{Evaluation in Mathematics: a reading of conceptions and an analysis of what is lived in the classroom}

\author{
Rosa Monteiro Paulo ${ }^{1}$ \\ Julio Cesar Augustus de Paula Santos ${ }^{2}$
}

\begin{abstract}
Resumo: Este artigo traz uma reflexão acerca da avaliação em Matemática, destacando os modos pelos quais essa avaliação pode vir a ser compreendida e discutida em um curso de formação de professores da área. Explicita-se como, a partir das situações de sala de aula, o olhar para as possibilidades da avaliação pode contribuir para a formação desse professor no que diz respeito ao compreendido pelos alunos. São analisadas três situações-problema, propostas aos alunos do curso de graduação em Matemática, cujo foco é o modo de avaliar. O olhar avaliativo e o fazer Matemática são entendidos como uma forma de o aluno voltar-se para o conteúdo matemático, abrindo-se ao que, no seu lidar cotidiano, se mostra. Diz-se da importância de se considerarem os "dados relevantes" e o "a ser conhecido" nas situações de avaliação que permitem, ao professor, ler a aprendizagem do aluno em seu modo de se expressar.
\end{abstract}

Palavras-chave: Educação Matemática. Avaliação da Aprendizagem Escolar. Conhecimento Matemático.

\begin{abstract}
This article allows some reflection on evaluation in Mathematics, highlighting the ways such evaluation may come to be understood and discussed in a Teacher Formation course. An attempt is made to unveil - in classroom situations - how looking at evaluation contributes to the formation of such teachers especially with regard to the analysis of what is understood by his/her students. Three problem situations have been analyzed, and discussed with Mathematics college degree students - whose focus is on the process of evaluation. The Evaluating look and taking up Mathematics are understood as ways for the student teacher to address the mathematical content, with him / her opening himself / herself to what his/her daily teaching shows. It shows the importance of considering the "relevant data" and that "to be known" in the evaluation situation allows the teacher to read the student's learning and ways of expression..
\end{abstract}

Keywords: Mathematical Education. School Learning Evaluation. Mathematical Knowledge.

\footnotetext{
${ }^{1}$ Licenciatura e Bacharelado em Ciências com Habilitação em Matemática, doutora em Educação Matemática. Docente, Departamento de Matemática, Universidade Estadual Paulista "Júlio de Mesquita Filho"- campus de Guaratinguetá. Guaratinguetá, SP, Brasil. <rosa@feg.unesp.br>

${ }^{2}$ Licenciatura em Matemática. Estagiário, Centro de Aperfeiçoamento do Ensino de Matemática, Instituto de Matemática e Estatística, Universidade de São Paulo. São Paulo, SP, Brasil. <julio.santos@grupo-sm.com>

${ }^{1}$ Rua Rio Tietê, 110

Jardim Nova Itaquá - Itaquaquecetuba, SP

08.599-220 


\section{Avaliação: em busca da compreensão do sentido presente nos textos lidos}

A vivência da sala de aula, nos cursos de Licenciatura em Matemática, nos faz questionar uma prática que, desde muito cedo, está presente na vida escolar: a avaliação. Em que medida ela pode ser compreendida, se visitada do interior do movimento em que se dá? O que se faz quando se diz que se está avaliando?

Essas são questões que se mostram significativas ao interrogarmos: o que é a avaliação? Ou, mais especificamente, o que é a avaliação em Matemática?

Para iniciar a investigação, visitamos alguns autores, tais como Esteban (2002), Hadji (1994), Hoffmann (1996, 1998), Luckesi (1995), Vasconcelos (1998), que discutem o assunto no contexto escolar, com o objetivo de compreender o que se diz sobre avaliação. Encontramos distintos significados para "avaliação": medir, atribuir valores, fazer análise de desempenho, entre outros. Do mesmo modo, encontramos diferentes exposições das "formas de avaliar", que nos remetem a modelos tidos como "formais", referindo-se àqueles que possuem critérios explícitos, procedimentos definidos e são fundamentados em pressupostos teóricos; ou "informais", que se caracterizam por sua forma espontânea e que, embora não tenham critérios explícitos, dão-se num movimento contínuo a partir de ações que visam o que é feito, as interações e a própria realidade vivida.

Dos autores visitados, optamos por trazer para a discussão, neste artigo, Luckesi (1995), para quem a avaliação pode ser entendida como "um juízo de qualidade sobre dados relevantes, tendo em vista uma tomada de decisão" (LUCKESI, 1995, p. 69, grifos nossos); e Hadji (1994), que situa a avaliação como sendo sempre relativa, isto é, como compreendendo uma relação entre dois polos, ou dois extremos, por exemplo, entre o que existe e o que é esperado, ou entre um desempenho real e um desempenho visado.

Luckesi (1995) e Hadji (1994) nos chamam a atenção pela semelhança entre seus enunciados. De onde advém a semelhança? Nos dizeres de Luckesi, compreendemos que o termo "qualidade" pode ser interpretado como uma relação em que um determinado ser se encontra com outros (CARAÇA, 2000). Se assim for entendido, o juízo de qualidade sobre os dados relevantes, que Luckesi traz para o contexto da avaliação, pode ser interpretado como um modo de atribuir valores às relações que são estabelecidas entre o desempenho real e o esperado, trazidos por Hadji (1994). Desse modo, o juízo torna-se um julgamento fundamentado e essencial que, ao considerar os dados relevantes, favorece a tomada de decisão ou o posicionamento diante dos resultados obtidos. Porém, em nosso entender, enquanto não for clareado o sentido de termos como "dados relevantes", "desempenho" ou, mesmo, dizer-se com relação "a que" se emite o "juízo", nada se estará dizendo sobre avaliar que possa ser significativo no processo vivido em sala de aula.

Então, a pergunta que nos move à investigação permanece e faz-se ainda mais presente: o que é avaliar? O que se faz quando se diz que se está avaliando?

É possível ver que, a princípio, essa pergunta posta para a investigação traz em si um pressuposto: avaliar é uma ação. O que faz essa ação? Ela busca ou emite um juízo - é o que nos dizem os autores citados. A que isso nos leva? Isso pode nos levar à compreensão do termo "avaliar", relacionado à ideia de "medir". 
Avaliação em Matemática: uma leitura...

Entretanto, os mesmos autores nos dizem que a ideia de associar a avaliação às tarefas de "medição" ou de "classificação", a partir da atribuição de valores, traz embutida uma concepção equivocada e ultrapassada, em que a avaliação visa ao aluno, ou melhor, visa à quantidade de informação que ele foi capaz de acumular e a qualidade ou o modo como essa informação é por ele expressa. Nesse modelo, ou concepção de avaliação, as provas são instrumentos primordiais, e os resultados obtidos, expressos numericamente, via de regra, são fontes importantes de dados para se ordenar ou classificar os alunos, segundo um parâmetro predefinido de aprendizagem ou de resultados esperados. Invade-nos uma dúvida: será mesmo uma concepção equivocada e ultrapassada?

O que significam, nos dias atuais, exames como ENADE (Exame Nacional de Desempenho de Estudantes), ENEM (Exame Nacional do Ensino Médio), PROVA BRASIL e SAEB (Sistema de Avaliação da Educação Básica), SARESP (Sistema de Avaliação do Rendimento Escolar do Estado de São Paulo) etc.? Esses “exames” consistem em uma avaliação que vem seguida de resultados. Isso não geraria nenhum espanto se a avaliação fosse considerada como a ação que tem em vista a "tomada de decisão". Mas o que fazer com esses resultados? Há uma ação efetiva que leve à modificação da prática?

Perrenoud (1999) nos diz que uma prática avaliativa somente poderá ser modificada num movimento conjunto que considere tanto o aspecto didático quanto o próprio sistema escolar. Para esse autor, há um "conjunto de equilíbrios frágeis" (PERRENOUD, 1999, p. 145), que exige uma coesão entre ensinar, aprender e avaliar; tais elementos devem ser considerados em harmonia numa prática efetiva.

Essa concepção liga-se ao sentido de avaliação que compreendemos na leitura de Luckesi (1995) e Hadji (1994): a qualidade dos dados relevantes deve levar à tomada de decisão. Talvez, se os resultados expressos na avaliação fossem considerados em relação ao esperado, não com a intenção de medir ou classificar, mas com o objetivo de levar à reflexão sobre a ação, de permitir voltar-se sobre o fazer e olhar de dentro o que está sendo feito, a prática efetiva da sala de aula pudesse ter um movimento de ampliação da construção do conhecimento.

Nesse movimento compreensivo, mostra-se, para nós, o sentido do termo "avaliar" como o que visa uma ação que é reflexiva e que permite a tomada de decisões. Avaliar, nesse sentido, diz do modo como o agir leva à possibilidade de conhecer, diz do como se propicia a abertura para acontecer o encontro com o objeto a ser conhecido. Resta clarear o sentido dessa abertura e do encontro que mencionamos.

\section{O “a ser conhecido": abertura e possibilidade de encontro}

Para Hoffmann (1998), a avaliação envolve uma relação com o processo de conhecimento do aluno e os modos pelos quais esse conhecimento é adquirido. Se concordarmos com a autora, mudamos a direção do olhar. Embora ainda com o objetivo de entender a avaliação, passamos a questionar que conhecimento é esse que será objeto de avaliação.

Para esclarecer a concepção de conhecimento que se assume no discurso deste texto, é preciso que façamos uma breve incursão pela Filosofia, mais precisamente, pelo pensamento 
de Martin Heidegger, uma vez que nele buscamos compreender e expressar o compreendido, ao falarmos de conbecimento.

Para Heidegger (1995a), o conhecimento tem seu fundamento na constituição ontológica da pré-sença enquanto ser-no-mundo. Ou, em suas palavras, "conhecer é um modo ontológico do ser-no-mundo" (HEIDEGGER, 1995a, p. 100). Com isso, o autor nos diz que conhecer é próprio do ser humano. Ou seja, o ser humano, enquanto ser que vive e convive com outros, tem afazeres, compromissos e tensões, mas está disposto a conhecer. O conhecer é um ato que se funda no já-ser-junto-ao-mundo do sujeito, e esse já-ser não é um ato de observação do que é dado ou do que está posto diante de nós, sujeitos passivos, espectadores do espetáculo do mundo. O já-ser diz de uma condição de ação em que o sujeito, ao se dispor para o mundo, busca conhecê-lo. Estando disposto, o sujeito que conhece é ativo. Ele faz do conhecer um ato de ser tomado pelo que conhece, de envolver-se na ação de conhecer, de ser chamado a conhecer. Essa é uma compreensão que, se levada para o âmbito da sala de aula, pode dizer do modo de o professor estar atento ao sentido que o seu aluno constrói e a sua importância no ato de conhecer.

Se nos voltamos para o conhecimento matemático e para a ação de conhecer em sala de aula, com esse olhar do sujeito disposto a conhecer, vemos que há de se ter uma preocupação com o modo de ser do sujeito que conhece, tornando-o um agente do seu conhecimento, fazendo-lhe ativo e participativo, tornando-o disposto, aberto a conhecer a Matemática. Nesse momento, entra para a discussão a função do professor como aquele que auxilia o conhecimento de algo. Nos dizeres de Bicudo (2005, p.50):

todo professor, por ser professor, encontra-se na posição de ensinar algo a alguém. [...] O ensinar está indissoluvelmente ligado a conhecer, pois ensinar implica um certo modo de comportar-se frente ao aluno, visando o seu conhecimento do corpo de conhecimentos que está sendo ensinado. Com isso fica nítida a importância do entendimento de como o ser humano conhece [...] e fica claro, também, que concepção de conhecimento está subjacente ao modo pelo qual o professor ensina, bem como ao modo pelo qual avalia o que o aluno elaborou a partir do ensinado.

A ação do professor em sala de aula deve estar voltada tanto para o corpo de conhecimentos com o qual trabalha quanto para o modo de conhecer esses conteúdos. Porém, isso também traz à tona uma possibilidade de questionar o objeto avaliado: o que se avalia, o conhecimento do aluno ou o modo como esse conhecimento foi desenvolvido?

\footnotetext{
${ }^{3}$ Pre-sença, para Heidegger, é o modo de ser do ente (homem) que se compreende pela existência. A existência está ligada ao mundo, que é o que nós percebemos e onde eu vivo. "É na pre-sença que o homem constrói o seu modo de ser, a sua existência, a sua história, etc. [...] esse ente que cada um de nós somos e que, entre outras, possui em seu ser a possibilidade de questionar, nós o designamos com o termo pre-sença..." (HEIDEGGER, 1995a, p. 38, grifos nossos).
} 
Avaliação em Matemática: uma leitura...

Para Heidegger (1995a), o conhecer exige um ser tomado pelo que se conhece, e pressupõe a disposição para o a ser conhecido que, em seu modo de ser, clama pelo conhecimento. Disso pode-se entender que o modo como essa disposição é favorecida é essencial ao ato de conhecer. Ou, dito de outra forma, no modo de ser-para-o-mundo, de dispor-se e voltar-se para aquilo que no mundo se mostra, é favorecido o encontro com o "a ser conhecido" e, na maneira de ser do sujeito que se volta para o que se mostra, se torna possível ver isso que, no dispor-se do sujeito para, lhe vem ao encontro. Esse veré, portanto, essencial ao conhecimento, pois é sempre um estar dirigido para... é um encarar o que é dado, é retirar um "ponto de vista" disso que vem ao encontro. Nesse ver, portanto, dá-se a percepção de algo como algo. O ente a ser conhecido se mostra tal qual ele é. "O perceber se realiza no modo de interpelar e discutir algo como algo" (HEIDEGGER, 1995a, p. 101) e dá-se o movimento de interpretação que determina o que vem a ser pronunciado, expresso, proposto. $\mathrm{Na}$ atividade de conhecer, o sujeito percebe, conserva e mantém o percebido. Se o a ser conbecido é o conteúdo matemático, por exemplo, ele mostra-se para o aluno se este o inquirir, voltar-se atentamente para ele, dispor-se a buscar, a perceber o que está encoberto, vendo, desocultando, compreendendo, interpretando e expressando isso que é visto.

Novamente perguntamos: o que é avaliado? Tanto a experiência docente quanto os autores lidos dizem-nos que é avaliado o modo de o sujeito expressar o percebido, que expõe uma compreensão. Ou seja, avalia-se a expressão, tomando o que é expresso como o conhecido. O que é percebido pelo sujeito é, de certa forma, expresso, e essa expressão é objeto de avaliação. Mas o que o expresso diz do conhecido? Como, na sala de aula, conhecemos o que é proposto? Como conhecemos o que a expressão do aluno revela do seu conhecimento matemático? Ou por um outro viés: como, enquanto professores, permitimos o encontro com $\mathrm{o}$ a ser conhecido ou favorecemos a percepção?

O vivenciado na prática cotidiana da sala de aula, quando lidamos com as situações de ensino e aprendizagem da Matemática no curso de graduação, mostra-nos um modo de conhecimento que já traz em si um padrão a ser atingido. Há modelos desejáveis aos quais se deve estar conforme, em equivalência. A expressão do que foi aprendido deve ser semelhante ao que foi ensinado. Ser semelhante aqui significa um modo de ser "tal ... como....". Esse "tal como", Heidegger (1995b) descreve como o re-presentar. "Re-presentar significa [...] deixar a coisa surgir diante de nós como objeto. O que surge [...] tem de atravessar um âmbito aberto de encontro" (HEIDEGGER, 1995b, p. 29) e mostrar-se tal como ele é, como algo permanente que é passível de ser compreendido e interpretado, no encontro do sujeito que conhece com o a ser conhecido. Ou seja, há um movimento compreensivo em que algo é revelado enquanto tal no percurso do vir ao encontro, no relacionamento, no estado de abertura do sujeito para o que se mostra a ser conhecido (objeto de conhecimento). A expressão do aluno revela esse movimento? A dúvida persiste: o que avaliamos?

$\mathrm{O}$ a ser conhecido, ou o conhecimento matemático a ser adquirido na sala de aula, diz respeito aos conteúdos pertencentes à Ciência Matemática e às suas aplicações, que são postos como sendo relevantes, segundo propostas e documentos oficiais. Porém, tão relevante quanto os conteúdos que são objetos de conhecimento é o próprio conhecimento ou o modo de dar-se o encontro do sujeito com o que deve ser conhecido nas aulas de Matemática. Falamos do "padrão a ser atingido", ou do que se espera que o aluno apresente como o conhecido, o que ele deve expressar. Mas o conhecimento, segundo o que dissemos até aqui, dá-se no 
encontro. Esse encontro, como nos permite compreender Bicudo (2005), pode ser favorecido pelo ensinar e é revelado pela expressão do aluno que busca re-presentar o que foi aprendido. Parece-nos, pois, que se avalia a re-presentação, o que o aluno expressa, buscando um modo de conformar (ou fazer equivaler) o que é conhecido com o que é esperado.

Ainda questionamos: ao avaliarmos o que é re-presentado pelo aluno, a expressão do que é conhecido, não avaliamos, também, o modo como isso foi favorecido?

Entendemos que a reflexão sobre o a ser conhecido nos põe no centro do movimento de compreensão da própria avaliação e nos leva aos dizeres de Perrenoud (1999), citado anteriormente, sobre a necessidade de coesão entre o aprender, ensinar e avaliar, que são momentos presentes no movimento do a ser conbecido. Se pretendermos ler o re-presentado como expressão do conhecido, resta saber como essa leitura pode ser feita. Qual a forma de ter acesso à expressão do conhecido?

\section{A avaliação em Matemática: processo? reflexão? mediação?}

Buriasco (2004) diz que a avaliação escolar "tem servido para reconhecer a presença ou não de determinado conhecimento" (BURIASCO, 2004, p. 244) por parte dos alunos. Mas como se dá esse reconhecimento? Pesquisas, como a de Moura e Palma (2006), mostram que a prova é um dos instrumentos mais utilizados para a avaliação em Matemática.

A prova, em geral, é um instrumento utilizado com o objetivo de verificar se o conteúdo trabalhado em aula, num certo período, foi aprendido pelo aluno. Ao que foi observado na prova atribui-se uma nota que expresse, numa escala de valoração, o grau de aprendizagem. O estudante que, no decorrer do ano, na média final, obtiver uma nota mínima estimada, ou considerada adequada segundo alguns critérios estabelecidos (modelo desejado), terá mais condições de passar para a próxima fase da aprendizagem matemática do que aquele que não tenha atingido essa média. Mede-se, portanto, o "nível de aprendizagem" do aluno. Com relação a quê? Algumas opções nos vêm à mente: talvez a sua capacidade de memorização, de repetição de regras, de expressão de modelos.

A esse respeito, Vasconcelos (1998) mostra-nos que o problema não está no fato de o professor utilizar "provas", mas sim em dar-lhes um caráter irreversível que expressa um resultado final e extingue as possibilidades de o aluno vir a superar dificuldades. Dessa forma, não favorece o seu desenvolvimento e condena-o ao fracasso, uma vez que o leva a diminuir a sua autoestima e sentir-se incapaz de aprender diante daquele que tudo sabe.

Bicudo (2005), ao falar das formas de autoritarismo que o professor pode assumir em sala de aula, leva-nos a crer que, tomar a avaliação no sentido acima explicitado, pode ser uma manifestação do que a autora denomina de "autoritarismo sutil", uma "violência cultural exercida pelos que pretensamente tudo sabem e ensinam aos que nada sabem" (Bicudo, 2005, p. 30). Essas palavras nos levam a questionar tanto os critérios nos quais devemos nos apoiar para avaliar o aluno em Matemática, quanto os motivos que levam os professores a assumirem a prova como seu principal instrumento de avaliação, especialmente nessa área. Será que somente com provas pode-se interpretar o que foi compreendido pelo aluno? Onde fica o a ser conhecido? O que, como professores, queremos avaliar? Como lidamos com os erros percebidos nos instrumentos ditos de avaliação? 
Avaliação em Matemática: uma leitura...

Tal como Heidegger (1995a) nos faz compreender o ato de conhecer como uma aquisição do conhecimento matemático que exige que o aluno seja o sujeito de sua ação, Bicudo (2005) nos mostra que é necessário estabelecer, em sala de aula, a comunicação entre quem ensina e quem aprende, dando condições para que o diálogo aconteça. É preciso ouvir o aluno, olhar para os seus modos de expressão, tornar-se disponível para o diálogo. Para essa autora, o diálogo é fundamental, uma vez que "a forma de pensar do aluno não coincide, de imediato, com a forma expressa pelo professor, havendo entre eles um desencontro" (BICUDO, 2005, p. 31). Considerar, na avaliação, o modo como a expressão revela o movimento da produção de significados, da produção do conhecimento pelo aluno, é dar oportunidade de ouvir a sua voz, é valorizar e "explorar os limites explicativos das representações construídas pelos alunos [...] resgatando a heurística do que é tido como um simples erro. Ao invés de extirpá-lo, partir dele" (BICUDO, 2005, p. 34).

Estudos como os de Cury (2006) e Esteban (2002) apontam modos de o professor fazer a valorização do diálogo em sala de aula, ao considerar, por exemplo, os erros cometidos pelos alunos como expressão que pode vir a orientar e fundamentar uma prática docente que se quer reflexiva e investigativa. Em ações dessa natureza, a expressão do aluno não é termômetro do "grau" ou "nível" de aprendizagem, é instrumento de orientação, de reflexão da situação vivida, de re-organização de ações.

Isso nos põe de volta no centro das reflexões sobre o que significa avaliar e nos remete às ações que apontam para o sentido da aprendizagem matemática. Veem-se, em pesquisadores da Educação Matemática que focam a avaliação, como Buriasco (2004), Moura e Palma (2006) e Sameshima (2006), discussões acerca de recursos para se proceder à avaliação. Esses pesquisadores destacam as provas escritas, os relatórios, as atividades lúdicas, os porffólios como instrumentos que possam vir a fornecer, ao professor, parâmetros para a realização de inferências sobre o modo como o aluno constrói o seu conhecimento matemático. As leituras de Buriasco (2004) nos permitem compreender como, a partir de situações abertas, o encontro com o a ser conhecido é favorecido, uma vez que se dá ao aluno a oportunidade de se expressar e, na expressão, ele revela o modo como conhece. Com isso, o foco orienta-se numa outra direção. A avaliação clama por interpretações. O olhar volta-se atento para o que é expresso e para o que o expresso indica: os dados relevantes, o modo como o aluno comunicase matematicamente. Expõe-se, gradativamente, o sentido da "qualidade dos dados relevantes" que se mostra no fazer Matemática do aluno, que se dispõe a realizar as situações propostas. Essas situações orientam-se pelo corpo de conhecimento matemático que o grau de escolaridade exige e pelo modo de os professores conhecerem os conteúdos que são apresentados. A avaliação ganha um ritmo, um movimento, que caminha na direção do encontro do aluno com o a ser conhecido. Revela-se, para nós, nesse contexto, uma possibilidade de compreensão da avaliação como movimento na direção do ensinado e do aprendido. Abre-se a oportunidade para a compreensão matemática mostrar-se como "estados de conhecimento que vão sendo atingidos por quem aprende ao pensar a Matemática" (BICUDO, 2005, p. 35).

Pode-se entender essa compreensão como um pro-jeto, um lançar-se à frente nas possibilidades abertas pelo lidar cotidiano da sala de aula e, como pro-jeto, requer tempo vivido, maturidade, discussão e um contínuo trabalho de interpretação. Abre-se, também para nós, um horizonte de compreensão do sentido do que é avaliar, que nos põe em condições de discutir com os nossos alunos do curso de graduação em Matemática, buscando o modo pelo 
Paulo, R. M.; Santos, J. C. A. P.

qual esses alunos, futuros professores, podem vir a compreender a avaliação. Descortina-se uma possibilidade de a avaliação ser compreendida como uma das ações relevantes para o ato de ensinar e de aprender.

\section{A avaliação posta em sala de aula: um voltar-se sobre o vivido}

Desenvolvemos, em sala de aula, um trabalho propiciado pela leitura e discussão dos textos citados neste artigo em torno de atividades usadas como modos de ler um estado de conhecimento do aluno ou como modo de avaliar a compreensão matemática ${ }^{4}$. As atividades foram desenvolvidas com alunos do curso de Licenciatura em Matemática na disciplina de Prática de Ensino I. O objetivo das atividades é discutir o conhecimento matemático favorecido em sua resolução e a avaliação que é possível mediante o que é expresso pelo aluno. Procurou-se diversificar as atividades de modo a apresentar situações que envolvessem uma matemática tratada desde as séries iniciais até o Ensino Superior. Isso foi feito com a intenção de levar o aluno da graduação em Matemática a compreender que, embora o foco da avaliação ou o a ser conhecido em Matemática mude, a intenção avaliativa que busca o conhecimento produzido deve permanecer. Ou seja, a resposta à pergunta: o que se avalia?, desde as séries iniciais até o Ensino Superior, pode ser compreendida no mesmo sentido.

Assim, como primeiro exercício, propomos a análise da situação que pode, a princípio, ser discutida nos primeiros anos de escolarização. Afinal, quem não conhece os "famosos problemas" de "mamãe foi à feira"?

Situação 1. Mamãe foi à feira com $\mathrm{R} \$ 23,00$. Veja, na tabela, quais notas mamãe leva em sua carteira:

\begin{tabular}{|c|c|}
\hline Quantidade de notas & Valor (R\$) \\
\hline 1 & 10,00 \\
2 & 5,00 \\
3 & 1,00 \\
\hline
\end{tabular}

Coloque verdadeiro (V) ou falso (F) e justifique sua resposta.

I. Quais notas ela poderá usar para pagar uma compra de $\mathrm{R} \$ 11,00$, sem receber troco?

( ) 1 nota de $\mathrm{R} \$ 10,00$ e 1 nota de $\mathrm{R} \$ 1,00$

( ) 1 nota de $\mathrm{R} \$ 10,00$ e 1 nota de $\mathrm{R} \$ 5,00$

\footnotetext{
${ }^{4}$ A situação 1 foi adaptada do SAEB 2001, disponível no sítio www.inep.gov.br; a situação 2 é uma adaptação de uma atividade proposta em livro didático de $5^{\mathrm{a}}$ série $\left(6^{\circ}\right.$ ano $)$ do Ensino Fundamental, e a situação 3 foi elaborada a partir de uma situação vivida por alunos de graduação em prova de Cálculo Diferencial e Integral. 
Avaliação em Matemática: uma leitura...

( ) 2 notas de $\mathrm{R} \$ 1,00$ e 1 nota de $\mathrm{R} \$ 10,00$

( ) 2 notas de $R \$ 5,00$ e 1 nota de $R \$ 10,00$

II. E se mamãe fosse à feira com $\mathrm{R} \$ 23,00$, distribuídos segundo as notas constantes da tabela abaixo, quais notas ela poderia usar para pagar a compra de $\mathrm{R} \$ 11,00$, considerando um troco de, no máximo, $R \$ 4,00$ ? Justifique sua opção.

\begin{tabular}{|c|c|}
\hline Quantidade de notas & Valor (R\$) \\
\hline 1 & 10,00 \\
2 & 5,00 \\
1 & 2,00 \\
1 & 1,00 \\
\hline
\end{tabular}

( ) 1 nota de $\mathrm{R} \$ 10,00$ e 1 nota de $\mathrm{R} \$ 1,00$

( ) 4 notas de $\mathrm{R} \$ 1,00 ; 1$ nota de $\mathrm{R} \$ 2,00$ e 1 nota de $\mathrm{R} \$ 5,00$

( ) 2 notas de $\mathrm{R} \$ 2,00 ; 2$ notas de $\mathrm{R} \$ 1,00$ e 1 nota de $\mathrm{R} \$ 5,00$

( ) 2 notas de $\mathrm{R} \$ 5,00$ e 1 nota de $\mathrm{R} \$ 1,00$

Nota-se que estas atividades pedem uma justificativa à resposta. Qual o objetivo dessa justificativa? As justificativas, sejam elas escritas ou orais, são modos de o aluno expor o que compreende da situação. As respostas dadas permitem ao aluno organizar o modo de pensar e, ao professor, compreender o movimento realizado nesse processo de interpretação e expressão do compreendido.

Se analisarmos a situação proposta, vemos que, no item I, espera-se do aluno um saber lidar com o sistema monetário e com as operações de adição e subtração que são usuais no já-ser-junto-ao-mundo, no lidar cotidiano, observando as condições exigidas pela situação, ou seja, fazendo uma leitura do que é requerido. Mas o esperado é condizente com o que é realizado pelo aluno? Se esperarmos essa correlação, voltamo-nos para uma situação de avaliação que espera a reprodução de modelos. Contrariamente, se nos abrimos para ouvir o aluno, podemos conhecer o que ele compreende da situação, entender como ele lida com o que é proposto, saber das dificuldades enfrentadas, conhecer a sua leitura do problema proposto.

Já, no item II, temos um exemplo de situação que permite o acesso ao modo de interpretação da proposta pelo aluno. Se questionarmos o que significa um troco máximo de $\mathrm{R} \$ 4,00$, perceberemos que a compreensão da expressão "troco máximo" abre possibilidades ao aluno para responder a questão, e suas respostas darão ao professor um modo de acesso ao que é conhecido. Resta, ainda, uma discussão possível: como avaliar as respostas dadas pelos alunos a questões dessa natureza?

Esse tipo de atividade, ao ser analisada pelo professor, revela formas distintas de pensar, dá abertura ao pensamento e à construção da linguagem pelo aluno, revela um modo de compreender Matemática que é expresso nas justificativas e que vai sendo apropriado pelo sujeito. Avalia-se a expressão do compreendido que revela, tanto no acerto quanto no erro, modos de o aluno dar sentido ao conteúdo matemático que lhe foi apresentado no contexto da situação. 
A natureza do proposto nesta tarefa levou a uma maior discussão. Possibilitou a discussão acerca dos dados relevantes, dos modos de expressão do aluno. Ou seja, ao discutirmos com os alunos da graduação as situações acima, procuramos direcionar o olhar do futuro professor de Matemática para as possibilidades de análise das respostas que deveriam respeitar e esgotar as possibilidades das representações dos alunos. Questões como "possibilidades de não compreensão do sentido de troco máximo" foram frequentes nas discussões do grupo. Procuramos voltar a atenção dos alunos para o buscado, para os dados relevantes, para o objeto de análise: a produção do aluno, e não a sua falta de produção. Insistimos que, na atividade, não se pretendia um julgamento, mas um exercício de ouvir e um respeito ao dizer do outro.

Queríamos, ainda, provocar um olhar em outra direção: aquele que buscasse uma análise do proposto, e não do feito. Ou seja, instigamos os alunos da graduação a analisarem a atividade proposta, a clareza do requerido, as possibilidades abertas pelo enunciado da tarefa. Isso levou à proposição de um novo problema.

Situação 2. João e Maria estavam querendo medir o comprimento de uma mesa retangular. Eles não tinham fita métrica ou régua, por isso usaram as próprias mãos. Para João, deu 16 palmos e, para Maria, 13 palmos. Podemos concluir que:

a) João tem o palmo mais curto.

b) Maria tem o palmo mais curto.

c) O palmo de João é igual ao palmo de Maria.

d) O palmo de João é maior que o palmo de Maria.

Nesse tipo de atividade, a análise voltou-se, mais especificamente, para o enunciado da questão. Os estudantes observaram que, pelo fato de se trabalhar com o "palmo" - uma unidade de medida não padronizada -, talvez tivéssemos um primeiro fator "complicador" na resolução da situação proposta. Eles consideraram, para a discussão, algumas possibilidades de respostas, já melhorando as condições de análise em relação ao feito na primeira questão proposta.

As análises convergiram para o que segue:

- Se a maioria dos alunos, para os quais o problema estava sendo proposto, escolhesse como resposta a alternativa "c", provavelmente, numa situação de avaliação do compreendido, iríamos deduzir que o enunciado não tinha ficado claro para eles, ou que a ideia de medida não havia sido compreendida, já que não perceberam diferenças entre as medidas de João e de Maria.

- Se as respostas se concentrassem nas alternativas "d" ou "b", haveria a possibilidade de os alunos terem sido levados ao erro pela ordem de grandeza do número: 16 é maior que 13.

Como proceder diante desses possíveis resultados? Os graduandos concluíram que, se o que interessa na avaliação é compreender o que está claro para o sujeito, temos uma expressão da situação, pois suas respostas serão, para o professor, um retrato do que foi compreendido. Mas, se consideramos que a ação de avaliar deve ser seguida de uma tomada de decisão, ou seja, diante do que o professor percebe na avaliação, novos rumos podem ser tomados, então interessa-nos identificar o que, na expressão dos alunos, não está coerente, 
Avaliação em Matemática: uma leitura...

para podermos mudar essa situação. O erro do aluno poderá indicar uma necessidade de trabalho com a ideia de medida para que o sentido do "16 vezes a mão de João" e "13 vezes a mão de Maria" seja clareado.

Esse agir, na sala de aula da graduação, levou à compreensão de que a avaliação não pode ser vista como um jogo, no qual se tenha, como objetivo, a reprodução - o modelo a ser re-presentado - e que, nesse jogo, o professor vá "colocando armadilhas" que não têm outra função senão a de dificultar e confundir o jogador em seu trajeto até o "verdadeiro e único fim": a resposta semelhante ao modelo esperado.

Considerando-se as análises das situações propostas, foi possível perceber que, na avaliação, abrem-se possibilidades de investigação da produção de significados e revelam-se novos modos de ver a ação do aluno e do professor no processo de conhecimento. Criam-se oportunidades de "o que surge vir ao encontro" no modo de questionar, uma vez que se visa à qualidade da informação. Isso, porém, não é simples de ser expresso por uma nota ou uma média final que é exigida pela cultura escolar vigente. No quadro atual e com nossa compreensão do que é avaliar, esbarramos em obstáculos culturais presentes no âmbito da escola que tornam necessária uma reflexão sobre a formação docente.

Considerando-se as palavras de Perrenoud (1999), a prática avaliativa pode ser resignificada se ela for vivenciada na formação docente de modo distinto do que é. Isso exige que ensinar, aprender e avaliar sejam atos complementares, e não dissociados. Exige que se busque um modo de o futuro professor valorizar o a ser conbecido e o modo de expressar o conhecimento adquirido.

A análise de questões como as que foram propostas acima pode levar, os futuros professores, a refletirem sobre a avaliação, entretanto ainda é necessário fazer com que eles se voltem para a qualidade do que eles próprios aprendem enquanto alunos do curso de Matemática. Isso nos leva à terceira situação proposta na sala de aula.

Situação 3. Observando o gráfico abaixo, calcule a área sob a curva $y=x^{2}$, para $o$ intervalo $0 \leq \mathrm{x} \leq 3$.

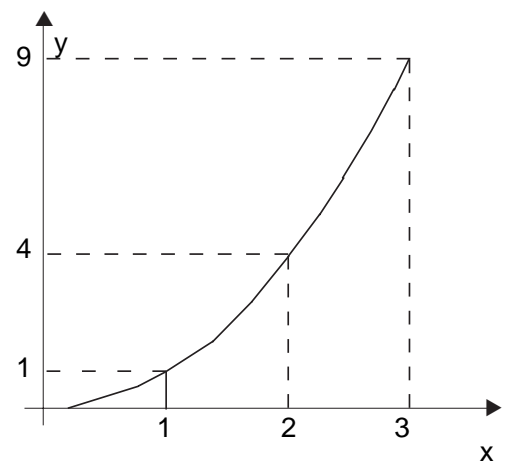

Esta atividade, apresentada a alunos de graduação em Matemática, tem como solução imediata algo do tipo: 


$$
\text { Área }=\int_{0}^{3} \mathrm{x}^{2} \mathrm{dx}=\left.\frac{\mathrm{x}^{3}}{3}\right|_{0} ^{3}=\left[\frac{27}{3}-0\right]=9 \text { u.a }
$$

Revelou-se, para nós, na resolução dessa atividade, um ponto fundamental sobre a compreensão da avaliação: o próprio curso de formação de professores de Matemática deve proporcionar ao aluno condições de conhecer o conteúdo matemático, de tal modo que ele seja capaz de investigar sobre a natureza desse conhecimento e de analisar o sentido da aprendizagem na área. Procuramos, então, levá-los a analisar o que seria possível de ser avaliado com essa atividade.

Em um primeiro momento, os estudantes pensaram, a partir do modo como a atividade mostrou-se para eles, que o que se pretendia era avaliar o conhecimento da técnica operatória. Mas um novo olhar para o "aprender Matemática" - que considere que "o ensino de Matemática não seja visto como um processo mas sim como um pro-jeto, um lançar-se para o futuro, para que os resultados desse ensino não sejam apenas a aprendizagem de algoritmos (que é processo), mas sejam compreensão" (BICUDO, 2005, p. 34) - fez-nos insistir na possibilidade de avaliação do conhecimento matemático para além da técnica.

Fizemos, então, pequenas alterações no enunciado da questão proposta com vistas à discussão do que poderia ser favorecido.

Modificando a situação 3. Observando o gráfico abaixo, faça uma estimativa da área sob a curva $y=x^{2}$, para o intervalo $0<x<3$. Você não pode integrar. Utilize outros recursos para determinar a área sob a curva.

(a) É possível melhorar essa estimativa? Como?

(b) Você pode determinar para qual valor a área sob a curva converge à medida que melhoramos as aproximações?

(c) O que você considera que muda, na questão, com esta alteração do enunciado?

Os graduandos concluíram que a restrição feita ao uso da integral foi o que propiciou a investigação, pois o aluno lança mão do sentido que o conteúdo tem para ele. Ou seja, é requerido que ele saiba "o que faz uma integral" e busque outros caminhos para encontrar respostas cada vez mais próximas ao que seria obtido pela integração. Discutimos, nessa oportunidade, o sentido da ação do professor em sala de aula como alguém que orienta a realização da atividade, intervindo quando é necessário. O aluno, por sua vez, é o agente da construção do seu conhecimento e deve assumir uma postura de disposição para ..., procurando relacionar conteúdos distintos de modo a tornar claro o que está sendo solicitado. $\mathrm{O}$ aluno assume, pois, uma posição primordial na busca pelo aprender.

Se nos voltamos para a questão inicial que motivou esta reflexão e perguntarmos novamente o que é a avaliação em Matemática, veremos que há uma multiplicidade de respostas possíveis, considerando-se o "lugar" de onde se olha o que é a aprendizagem matemática. Se compreendermos que a aprendizagem é um movimento que leva à compreensão, interpretação e expressão do compreendido, a avaliação ganha um lugar de destaque na pré-ocupação do professor, pois será vista como uma ação que exige a tomada de decisões e visa aos dados 
Avaliação em Matemática: uma leitura...

relevantes que apontam para o modo de compreensão do aluno. O foco da atenção do professor vai para as possibilidades de aprender Matemática que são abertas no cotidiano da sala de aula, na organização das atividades e na forma de o expresso revelar-se.

Nesse movimento de análise que busca a compreensão da avaliação, que pergunta pelo julgamento que se faz ao estarmos avaliando a aprendizagem matemática do aluno, passamos a compreender a ação de avaliar como uma crítica.

Em que sentido tomamos essa crítica? No sentido a ela atribuído por Heidegger (2001), que tanto pode assumir uma postura negativa quanto positiva. Crítica é uma

palavra que vem do grego $\chi \rho \imath v \varepsilon \imath v$ isto é, diferenciar. Tirar algo de algo, geralmente algo mais baixo de algo mais alto. Na lógica este procedimento chama-se um julgamento, um juízo. Ambas as afirmações contêm uma crítica negativa. (HEIDEGGER, 2001, p. 159)

Se assumirmos a avaliação como um julgamento que busca aproximar o que é real do que é desejado (tirar algo mais baixo de algo mais alto), ela será uma crítica negativa, uma vez que destacará as "falhas" que são cometidas pelos alunos que não se aproximam do modelo desejado. Volta-se ao julgamento que mede, compara e procura aproximar.

Contrariamente, se a avaliação for uma crítica positiva, tal qual essa critica pode ser compreendida em Heidegger, ela "tem o objetivo de promover o objeto de que trata. Ela é sempre uma indicação de novas possibilidades objetivas" (HEIDEGGER, 2001, p. 159). Ela - a avaliação entendida como critica positiva - busca uma compreensão do sentido que algo fez para o sujeito.

A avaliação, se vista do interior do movimento no qual ela acontece, favorece a crítica positiva, a multiplicidade de olhares que se apóia no fundamento do que é percebido, compreendido, interpretado e expresso. Ou seja, a avaliação, enquanto crítica, pode ser realizada como busca da compreensão tanto pelo aluno que dá sentido à sua aprendizagem, quanto pelo professor que a utiliza para orientar as ações em sala de aula, permitindo a construção do conhecimento matemático.

\section{A avaliação: re-visitando suas facetas e ampliando a compreensão em busca de uma síntese}

$\mathrm{Na}$ busca da compreensão do a ser conhecido e da postura do sujeito que conhece, voltamo-nos para a questão da avaliação e procuramos compreender a qualidade dos dados relevantes para os quais Luckesi (1995) nos chama a atenção no ato de avaliar. Quais seriam os dados relevantes para os quais se deve emitir um juízo ao avaliarmos em Matemática? Que qualidade ou quais relações devem ser propiciadas nesse processo de conhecer?

O a ser conbecido, em Matemática, exige um modo de comportar-se do sujeito que conhece que lhe permita estabelecer relações entre os próprios conteúdos matemáticos e entre esses conteúdos e o mundo vivido. A avaliação deveria, portanto, desvelar esses aspectos do conhecer Matemática, desvelar os significados do que foi compreendido e expresso, do que foi re-presentado. 
Paulo, R. M.; Santos, J. C. A. P.

Mas, se tomarmos a relação pressuposta na avaliação, de que nos fala Hadji (1994), entre o desempenho real e o desempenho visado, busca-se, ao avaliar, uma adequação entre o que é objetivamente dado, que é passível de ser conhecido intelectualmente por meio de conceitos, e o que é conhecido. Porém o conhecimento do qual falamos mostra um sujeito que se envolve com o conhecer, que clareia ou des-oculta o que é dado a conhecer, que é ativo e crítico, disposto a conhecer, a fazer descobertas e estabelecer relações no movimento de aprendizagem. A avaliação, incidindo sobre esses dados, apresenta-nos resultados que podem ser, novamente, objetos de avaliação para a tomada de decisão. Essa tomada de decisão indica o que, como professores, devemos fazer para que o ensino favoreça a abertura e propicie o encontro com o a ser conbecido e a relação crítica e reflexiva que mostre os objetos matemáticos tais quais eles são.

Abre-se uma concepção de avaliação que põe ênfase no conhecimento, que busca os significados da atuação individual e coletiva, que não visa "medir" a distância entre o ideal e o real, mas que assinala e permite compreender os padrões vivenciados em sala de aula. Mostrase, para nós, o que é avaliar bem como o que se faz quando se está avaliando: avaliar é um meio de se conduzir ao a ser conbecido, e essa condução é favorecida pelo saber competente do aluno e pela disponibilidade de diálogo do professor. Essa clareza, se presente nos cursos de formação de professores de Matemática, se tomada como um exercício de análise, pode vir a favorecer a compreensão da avaliação como uma crítica positiva que promove novas possibilidades, mas também que abre caminhos inesperados para os quais pode-se não estar pronto...

\section{Referências}

BICUDO, M. A. V. (Org.). Educação matemática. São Paulo: Centauro, 2005.

BURIASCO, R. L. C. Análise da produção escrita: a busca do conhecimento escondido. In: ENCONTRO NACIONAL DE DIDATICA E PRÁTICA DE ENSINO, 7., 2004, Curitiba. Anais... Curitiba, 2004. v. 3. p. 243-251.

CARAÇA, B. J. Conceitos fundamentais da matemática. 4. ed. Lisboa: Gradiva, 2000.

CURY, H. N. Análise de erros em disciplinas matemáticas de cursos superiores. In: SEMINÁRIO INTERNACIONAL DE PESQUISA EM EDUCAÇÃO MATEMÁTICA, 3., 2006, Águas de Lindóia. Anais... São Paulo: SBEM, 2006. 1 cd-rom.

ESTEBAN, M. T. Avaliar: ato tecido pelas imprecisões do cotidiano. In: GARCIA, R. L. (Org.). Novos olhares sobre a alfabetização. São Paulo: Cortez, 2001. p. 175-192. Disponível em: < http://www.anped.org.br/reunioes/23/textos/0611t.PDF>. Acesso em: 20 maio 2002.

A avaliação no processo ensino/aprendizagem: os desafios postos pelas múltiplas faces do cotidiano. Revista Brasileira de Educação, Rio de Janeiro, n. 19, p. 129-137, 2002. Disponível em: < http://189.1.169.50/rbe/rbedigital/RBDE19/

RBDE19_12_ESPACO_ABERTO_-_MARIA_TERESA_ESTEBAN.pdf $>$. Acesso em: 20 maio 2009 . 
Avaliação em Matemática: uma leitura...

HADJI, C. A avaliação, regras do jogo: das intenções aos instrumentos. Porto: Porto Editora, 1994.

HEIDEGGER, M. Seminários de Zollikon. Petrópolis: Vozes, 2001.

Ser e tempo. 3. ed. Petrópolis: Vozes, 1995a.

Sobre a essência da verdade. Porto: Porto Editora, 1995b.

HOFFMANN, J. Avaliação mediadora: uma prática em construção da pré-escola à universidade. 8. ed. Porto Alegre: Mediação, 1996.

1998.

Ponto e contrapontos: do pensar ao agir em avaliação. Porto Alegre: Mediação,

LUCKESI, C. C. Avaliação da aprendizagem escolar. São Paulo: Cortez, 1995.

MOURA, A. R. L.; PALMA, R. C. D. A avaliação em matemática: lembranças da trajetória escolar de alunos de Pedagogia. In: SEMINÁRIO INTERNACIONAL DE PESQUISA EM EDUCAÇÃO MATEMÁTICA, 3., 2006, Águas de Lindóia. Anais... São Paulo: SBEM, 2006. p. 1-16.

PERRENOUD, P. Avaliação da excelência a regulação da aprendizagem: entre duas lógicas. Porto Alegre: Artes Médicas, 1999.

SAMESHIMA, D. C. T. Compreendendo a avaliação da aprendizagem matemática. In: SEMINÁRIO INTERNACIONAL DE PESQUISA EM EDUCAÇÃO MATEMÁTICA, 3., 2006, Águas de Lindóia. Anais... São Paulo: SBEM, 2006. p. 32-48.

VASCONCELOS, C. S. Avaliação da aprendizagem: práticas de mudança por uma práxis transformadora. São Paulo: Libertad, 1998.

Artigo recebido em julho de 2010 e aceito em janeiro de 2011. 